Andrea Lizeth López Flores 


\section{Arte y belleza: sentido cultural y naturaleza humana}

\section{Introducción}

Larry Shiner iniciadas a principios del siglo XVIII tienen, en el pensamiento filosófico, una tradición un tanto más antigua pues, aun cuando no existía una pregunta explícita sobre qué es el arte, había, ya desde Platón, una profunda reflexión respecto a la creación artística, así como sobre el papel que el artista y su obra desempeñaban dentro de su sociedad, papel que para el filósofo adquiría un carácter negativo cuando se ocupaba de la imitación de las formas o ideas verdaderas; es decir, cuando se trataba del arte imitativo, ya que al ser el mundo una copia de dichas ideas y, a su vez, ser esta copia la representada por el artista en su obra, esta última sería, entonces, la copia de una copia, la representación de algo que ya de por sí no es verdadero.

Esta imitación, afirma, es la que realizaban los pintores y los poetas, de quienes incluso llegaría a decir que debían ser desterrados del Estado por alejar al alma de las ideas verdaderas, y los consideraba los terceros en relación con la verdad; señala, entonces: "Es justo que los ataquemos y que lo pongamos como correlato del pintor, pues se le asemejan en que produce cosas inferiores en relación con la verdad... trata con la parte inferior del alma y no con la mejor. Y así también es en justicia que no la admitiremos en un Estado que vaya a ser bien legislado." ${ }^{1}$

\section{Lo histórico}

Al señalar al pintor y al poeta como los terceros en relación con la verdad, Platón lleva a cabo una distinción importante que preva-

1 Platón, La República, Libro X, Gredos, Madrid, 2014, p. 215. 
lecerá hasta avanzado el Renacimiento, a saber, la distinción entre estos que pasarían a ser considerados artistas y los artesanos, estos últimos considerados segundos en relación con la verdad, puesto que conocen de manera más directa el uso de los objetos que producen ya que lo conocen a través de la orden directa de quien se sirve de ellos, quienes los dotan de la idea de lo que es bueno o malo en aquéllos, en función de su uso, por lo que se puede señalar que durante este periodo, el papel del artesano adquiere una mayor importancia en tanto que se encuentra más cercano a la idea verdadera. Así pues, la pregunta implícita sobre qué es el arte, anterior a cualquier esbozo de una teoría estética sistemática, se respondería en función del papel que desempeñara dentro de la sociedad de su tiempo. En el arte clásico, por ejemplo, aun pese a la concepción peyorativa de Platón, el arte mimético cumplía con una función de carácter, en gran medida, político y religioso, pues permitía dar cuenta de acontecimientos de gran estima para la sociedad, como las batallas de sus héroes y la concepción sobre sus dioses, y esto hizo prevalecer al arte por sobre las consideraciones en torno a él.

A lo largo de la Edad Media, el arte estuvo también estrechamente relacionado con una función religiosa. El papel del artista continuaba supeditado a las reglas establecidas por el uso que había de darse a su obra, reglas que -al igual que lo que ya señalaba Platón respecto a la artesanía - provenían de quien había de emplear las obras y que, por ende, sabía lo que para ellas era bueno o malo. En la Edad Media, esto consistió, en mayor medida, en la finalidad de llevar el mensaje religioso a públicos fuera del ámbito teológico, por lo que la capacidad creativa del artista y las reflexiones en torno a su labor no tenían gran lugar, sino su capacidad para satisfacer los lineamientos establecidos por quien solicitaba sus obras.

Ya en el Renacimiento, pese a que el papel del artista continúa atado de cierta manera a reglas establecidas por los consumidores de sus obras, comienza a figurar una reflexión más explícita respecto a aquello que caracteriza la labor artística. Esa reflexión es llevada a cabo desde el arte mismo, es decir, desde el artista, acerca ya no sólo de su papel en la sociedad, sino de la finalidad misma del arte, a partir de una adecuación de los cánones clásicos, pero no ya con la finalidad de representar una idea verdadera de los dioses, por dar un ejemplo, sino por la belleza y el valor del arte per se. Será, precisamente, la belleza la que inaugure una nueva etapa respecto 
a la pregunta por el arte, ya que es a través de ella que el artista empieza a replantear su papel y el de su obra, comenzando a considerarla como valiosa por sí misma - reflexión como la que hace Da Vinci en su tratado sobre la pintura- y tomando ya como parte fundamental de ella, no sólo el uso de la técnica y el seguimiento de las reglas, sino su capacidad para reinventarlas y perfeccionarlas, es decir, es a partir de ese momento cuando la capacidad creativa del artista ocupará un lugar predominante dentro de la obra.

Sin embargo, la verdadera necesidad de explicar la labor artística, así como lo que el arte era capaz de producir en el espectador - como ya se mencionaba un poco al principio- no surge sino hasta el siglo XVIII, una vez instauradas las bellas artes; es decir, luego de que se admitiese que las obras tenían valor por sí mismas y se crearan los derechos de autor y el museo, ${ }^{2}$ lo que llevó no sólo a los teóricos del arte, que para aquel entonces conformaban una elite bastante más cerrada que en nuestros días, sino también a la filosofía a buscar aquellos elementos que dotasen de sentido tanto a la obra de arte como a lo que se pudiese señalar respecto a ella. La filosofía en aquel entonces, más que tomar como eje central la reflexión en torno a qué es el arte, dirigió su enfoque a aquellos elementos de la obra que llevasen no sólo al artista, sino también al espectador, a considerarle como bella o valiosa, es decir, sobre aquello que conformase nuestros juicios estéticos.

\section{Hutcheson}

Un autor que sería de gran importancia en lo referente a estas reflexiones fue Francis Hutcheson quien, en su obra Investigación sobre el origen de nuestras ideas de belleza y virtud, intenta demostrar que existe un sentido interno en los hombres que les permite captar, incluso de manera involuntaria, la belleza de las cosas, entiéndase con esto la belleza presente tanto en las obras de la naturaleza como en las obras de la creación humana. Para él, nuestro sentido de la belleza no es dependiente de nuestros sentidos externos, sino sólo de algo propio e inherente a nuestra naturaleza; afirma, entonces, que "el placer que sentimos con los objetos bellos no deriva

2 Cfr. Shiner, Larry, La invención del arte. Una historia cultural, Paidós, España, 2004, p. 128. 
de la costumbre, la educación y/o el ejemplo, sino el sentido de la belleza."3 Para Hutcheson - quien a su vez retoma algunos de los elementos de las ideas simples y compuestas de Locke, pero con ciertos cambios que le permitan introducir su teoría del sentido interno de la belleza- lo que proviene de la costumbre o la educación se asemeja a las ideas que provienen del sentido externo, pero considera que para que podamos entender lo que proviene de estas ideas, requerimos necesariamente de un sentido interno que nos permita entenderlas, una facultad innata que permite "reaccionar con placer cuando los sentidos externos perciben determinadas propiedades." ${ }^{4}$ Considera que hay dos maquinarias mentales que funcionan de manera semejante, pero que, sin embargo, reaccionan de forma distinta, una de ellas ante estímulos externos y otra mediante facultades inherentes a nuestra naturaleza. Esta facultad inherente, nos dice, consiste en la capacidad de encontrar uniformidad dentro de la variedad.

Hutcheson tiene, a su vez, gran influencia en las ideas respecto al gusto de David Hume, ya que para este autor nuestras ideas de belleza también parten de un sentido externo; sin embargo, existe una gran diferencia respecto a la teoría de Hutcheson, quien reduce el sentido interno de la belleza a una sola cualidad, mientras que para Hume las ideas de belleza difieren en gran medida en todas las personas, incluso si éstas se desenvuelven en un contexto con educación y prejuicios semejantes, ya que existe una imposibilidad de obtener una norma del gusto, es decir, no podemos señalar que todas las personas experimentan el mismo arte de la misma manera. Esto se debe a que, al provenir nuestros juicios estéticos de los sentidos externos, aquéllos no tienen referencia en nada fuera de sí mismos, por lo que no puede haber una relación respecto a lo que despierta el sentido de belleza o placer en un individuo y en otro. Por ejemplo, existen personas a las que les resulta sumamente difícil, o incluso desagradable, encontrarse con obras que no representen algo existente en la realidad, y que constituyan sólo el fruto de la imaginación, de la excentricidad o la rebeldía de sus autores.

Como puede observarse, la postura de Hume permite que al emitir un juicio estético, éste no tenga que ser necesariamente

3 Dickie, George, El siglo del gusto, la odisea filosófica del gusto en el siglo XVIII (trad. Francisco Calvo Garzón), La balsa de la medusa, España, 2003, p. 22.

4 Ibidem p. 23. 
compartido de manera universal, ya que se encuentra fundamentado sólo $-y$ en esto coincidirá con su postura acerca de la moral- en el sentimiento y nada más. ${ }^{5}$

Como puede observarse, estas dos posturas filosóficas toman como su centro de atención al individuo que realiza el juicio estético, a su naturaleza, ya sea apelando a un sentido interno e innato o a sus sentidos externos; sin embargo, tras la llegada de los movimientos artísticos de vanguardia que se encontraban estrechamente vinculados a un discurso disruptivo y a un contexto histórico delimitado - en el que se apelaba a la ruptura con los cánones tradicionales, a lo que el individuo estaba tan acostumbrado a contemplar en las obras, como la belleza, la composición, la perspectiva, la forma, etcétera-, la filosofía y la teoría del arte tuvieron que replantear nuevamente aquello que ha de considerarse como valioso respecto a las obras, así como la validez de nuestros juicios estéticos, ya que por su mismo carácter disruptivo, el arte de vanguardia parecía permitir que prácticamente cualquier objeto se convirtiese en una obra de arte.

Obras como las creadas por el dadaísmo, La fuente de Marcel Duchamp y las obras del arte pop desencadenaron un nuevo planteamiento teórico respecto al arte, y una nueva pregunta en torno a ella; ya no se trataba de indagar aquello que es el arte, ni tampoco sobre qué elementos del individuo lo llevan a considerarla como bella o placentera, sino sobre qué elementos debía tener la obra de arte para ser considerada como tal, es decir, cómo distinguir objetos comunes del verdadero objeto artístico, en qué valores radicaba su sentido.

\section{Danto}

Es entonces que se desarrollan teorías un tanto más prescriptivas, como por ejemplo la de Arthur Danto quien, impresionado por las obras de arte pop, en especial la producción de Andy Warhol y su Caja Brillo, plantea que la validez de las obras se encuentra estrechamente relacionada a que éstas se ubiquen dentro de un contexto específico, es decir, que se ubiquen dentro del mundo del arte, y para su comprensión se requiere, en cierta medida, de un

5 Cfr. Rachels, James, Introducción a la filosofía moral, México, 2006, p. 65. 
conocimiento de la teoría del arte a la que dicha manifestación se relaciona; así nos dice que:

Lo que finalmente hace la diferencia entre una caja de Brillo y una obra de arte que consiste en una caja de Brillo es, entonces, una cierta teoría del arte. Es la teoría que la hace entrar en el mundo del arte, y le impide reducirse a no ser más que lo que el objeto real es (en otro sentido del es que el de la identificación artística). Seguramente, sin la teoría, no la veríamos probablemente como arte, y para poder verla como formando parte del mundo del arte, debemos dominar una buena parte de la teoría artística. ${ }^{6}$

La teoría del arte de Danto deriva, a su vez, en teorías del arte institucionales como la de George Dickie, sin embargo, el problema de cómo distinguir los objetos artísticos de los que no lo son continúa siendo un tema de gran discusión dentro del arte contemporáneo, ya que incluso la validez que les otorga el mundo del arte, llámese museo, curador o crítico, parece poco confiable cuando el artista contemporáneo expone al público obras que parecen absolutamente carentes de significado, incomprensibles para quien desconoce el discurso existente tras de ellas o que incluso encuentra las piezas demasiado forzadas por los curadores para dotarlas de un significado. No obstante, existe también otro tipo de público que, aun cuando desconoce los elementos que se encuentran detrás de las obras, es capaz de experimentar una respuesta estética inmediata a ellas, entendiéndose por respuesta estética un sentimiento de placer o displacer en el enfrentamiento con las obras, por lo que ambas vertientes -ya sea la que se opone totalmente al arte contemporáneo por encontrarlo carente de significado o la que halla en él ciertos elementos capaces de generarnos una respuesta estética- mantienen viva la discusión.

Ahora bien, ¿cómo podríamos dar cuenta de por qué sigue habiendo tanto desacuerdo en cuanto a lo que a nuestros juicios estéticos se refiere? ¿Por qué existen opiniones que optan más por los cánones tradicionales mientras que otras encuentran valiosos ciertos elementos del arte contemporáneo? Estas diferencias, como puede notarse, regresan su punto focal al individuo, dejando un

6 Danto, Arthur C, El mundo del arte [en línea] https://es.scribd.com/ doc/55496775/El-Mundo-Del-Arte-Arthur-Danto 
tanto de lado lo que hace valioso a las obras; así, la línea principal sobre la que discurrirán será la de por qué nos sentimos atraídos por el arte, qué nos lleva a la necesidad de crear arte, lo que de algún modo, aunque tampoco de manera explícita, podría responder las preguntas anteriores, a saber, la de qué es el arte y por qué algunos objetos nos resultan placenteros estéticamente hablando, ya que es el individuo quien dota de sentido a ambas interrogantes.

\section{Dutton}

Una de las respuestas principales a esta nueva problemática es la que plantea Denis Dutton en su obra El instinto del arte, en la que habla acerca de los rasgos evolutivos que han llevado al hombre a desarrollar sus juicios estéticos, ya que afirma que lo estético -de un modo semejante a como ocurre con la selección sexual que se expresa a través de lo erótico- "surge espontáneamente como fuente de placer en todas las culturas del planeta." Dutton no deja de lado las problemáticas anteriores respecto al arte, pero le concibe a partir de una relación entre la biología humana y la cultura; esta última, nos dice, puede dotarnos de la capacidad de habituarnos y sentirnos complacidos con ciertas formas de expresión artística, o por el contrario, llevarnos a censurar otras tantas, pero no puede dotarnos de una verdadera capacidad de apreciar o detestar las obras; es decir, yo puedo conocer los lineamientos o reglas vigentes que hacen que, dentro de mi contexto ( $y$ hay que poner especial atención a este punto), una obra sea apreciada como artísticamente valiosa y que otras tantas cosas que, al no seguir dichos lineamientos, sean catalogadas como desagradables y, a partir de dicho conocimiento, puedo emitir un juicio de una obra específica, pero este juicio será estrictamente basado en los lineamientos establecidos y en mi conocimiento y comprensión de los mismos, por lo que no me representará una verdadera experiencia estética. Desde ésta perspectiva, las teorías institucionales del arte no dan cuenta suficiente de aquello que para el individuo constituiría la verdadera experiencia estética, pero esto tampoco se lograría al reducirla a meras relaciones entre circuitos neuronales placenteros; sin embargo, al menos en lo que respecta a la teoría del arte de Dutton, éste no es un factor que se pueda pasar por alto, ya que esto permitiría 
explicar por qué ciertos elementos del arte nos resultan agradables, independientemente del contexto de las obras.

$\mathrm{Al}$ enfrentarnos a una obra, hay que tener en cuenta, además, una distinción fundamental: la que hay entre el interpretar las emociones humanas - es decir, el asociar la obra con tal o cual momento o emoción particular del sujeto- y el verdadero enfrentarse con la obra -enfrentamiento que, como tanto se ha señalado en la filosofía es, al menos en primer momento, libre de toda asociación.

En lo referente a la distinción entre arte y artesanía, o entre arte y objeto común, Dutton desarrolla otras características que pueden llevarnos a resolver no sólo esa problemática, sino otras que se encuentran conectadas con ella. Para distinguir el arte de la artesanía, una de las respuestas posibles es que la última tiene desde sus inicios un fin y un método determinado, mientras que la primera goza de la libertad y capacidad creativa del artista, pues aunque éste posea una visión preconcebida de aquello que espera que sea el resultado de su obra, ésta puede modificarse en su desarrollo, y a pesar de ello seguir constituyendo una verdadera obra de arte.

Por otro lado, en lo que respecta a la obra de arte y a su relación con las estructuras sociales - no en referencia a las instituciones y las reglas que le sirven de sustento, sino en tanto que, como seres sociales, nos resulte más completa una experiencia estética que es compartida y validada por otros-, Dutton señala que este aspecto no le es esencial al arte, pero reconoce que hay claras asociaciones en ambos rubros. No obstante, afirma que esto puede deberse a la búsqueda de una sensación de pertenencia, que puede también ser explicada a través de la composición biológica humana.

Dutton aborda por qué nos sentimos atraídos por el arte, según nuestros rasgos biológicos evolutivos; sin embargo, a mi parecer, sigue sin dar cuenta de manera amplia de por qué se dan las variaciones en lo que genera una respuesta estética en tanto que individuos.

Una respuesta a este problema puede llevarse a cabo al adentrarse aún más a fondo en la naturaleza humana, es decir, en aquellos rasgos que nos determinan, pero no sólo en cuanto especie, sino como individuos. Así pues, esta labor estética requiere ya de una serie de conocimientos que, aunque aplicados al terreno del arte, no le conciernen exclusivamente, pero que pueden ayudar a dar una mejor cuenta de en qué se fundamenta aquello que podemos experimentar y expresar en materia de arte. 
Esta labor lleva ya algún tiempo desarrollándose, en especial en lo que respecta a las artes visuales, y uno de sus principales exponentes, el neurobiólogo Samir Zeki, explica que la función de la parte visual del cerebro, la creación y la experiencia estética se encuentran estrechamente vinculadas ya que, en primer lugar, un artista, que es el primer receptor de la obra, se siente satisfecho con ella una vez que ésta complace a su cerebro y lo mismo ocurre con el espectador, quien, aun pese a la carga teórica que posea, por sencilla o amplia que ésta sea, en primera instancia, puede tener un primer enfrentamiento con la obra y generar un juicio en torno a ella, que es exclusivamente de carácter sensorial.

Esta respuesta, señala, no le corresponde a una corriente artística específica, sino a ciertos elementos presentes en cada una de las obras y que, independientemente de nuestro conocimiento acerca de ellas, son capaces de activar una serie de reacciones a nivel cerebral que influyen directamente en nuestros juicios estéticos. Estos elementos son, entre otros, la forma, el color y el movimiento. Tales atributos, señala, activan distintas funciones a nivel biológico, y generan así un mayor flujo sanguíneo en áreas morfológicamente diferenciadas del cerebro, que no reaccionan necesariamente como un conjunto. Es decir, una obra puede tener color, movimiento y forma, sin embargo, la reacción provocada en el cerebro de un individuo puede deberse de manera exclusiva al uso del color, y ser indiferente al resto de los elementos de una obra, la que además puede tener consigo la relación a un discurso, pero dicha relación corresponde ya a otro plano de nuestra organización cerebral.

Así, por ejemplo, yo puedo tener un primer enfrentamiento con la obra La Guerra (1916) del pintor futurista Giacomo Balla, y sentirme impresionada por ella, y decir que es placentera estéticamente hablando sin tener un gran conocimiento acerca de en qué consistió el movimiento futurista, ni del discurso al que al que estaba ligado, ni tampoco de ningún otro canon anterior, sino sólo por el hecho de que la estructura de la obra genera el aumento de flujo sanguíneo en las áreas cerebrales que reaccionan ante el color y puede que exclusivamente por ello la obra me resulte agradable, ya que: "El tipo de información que tiene que descartar o sacrificar el cerebro al obtener la esencia de un atributo, por ejemplo el color, es muy diferente del tipo de información que ha de descartar para obtener la esencia de otro atributo, por ejemplo el tamaño; en el 
primer caso, hay que discernir la composición precisa de longitudes de onda de la luz que proviene de una superficie y, en el segundo caso la distancia visual."

\section{Conclusión}

Puede, sin embargo, objetarse que a partir de lo anterior, yo puedo percibir estéticamente cualquier tipo de objeto a partir de su color, su forma o su movimiento, es por ello que considero que ambas vertientes -la que aborda el arte a partir de las estructuras sociales en las que se encuentra respaldada, y la que le analiza desde una perspectiva más relacionada con el individuo que reacciona ante ella- funcionan como un conjunto que nos permite entender de una manera más amplia las variaciones y los desacuerdos que se generan en lo que nos resulta agradable o desagradable en una obra artística, por lo que de manera muy general, podemos concluir lo siguiente.

Hay tres formas de hablar sobre la experiencia estética

1. A partir de nuestras estructuras sociales, puesto que por muy general que sea la idea que tenemos respecto al arte, ésta funge como base anticipada de nuestra experiencia estética, nos dice que el objeto al que vamos a enfrentarnos es un objeto artístico.

2. La forma anestética. Ésta se encuentra relacionada a la intención del artista, pero también puede ser el resultado de una respuesta indiferente del espectador al enfrentarse a la obra.

3. Enfrentamiento neurobiológico. Respuesta que puede desarrollarse de forma inmediata y que no depende necesariamente de una carga teórica compleja.

Finalmente, cabe señalar que la primera y la tercera forma no son mutuamente excluyentes.

7 Zeki, Semir, Visión Interior. Una investigación sobre el arte y el cerebro, La balsa de la medusa, España, 2005, p. 98. 
